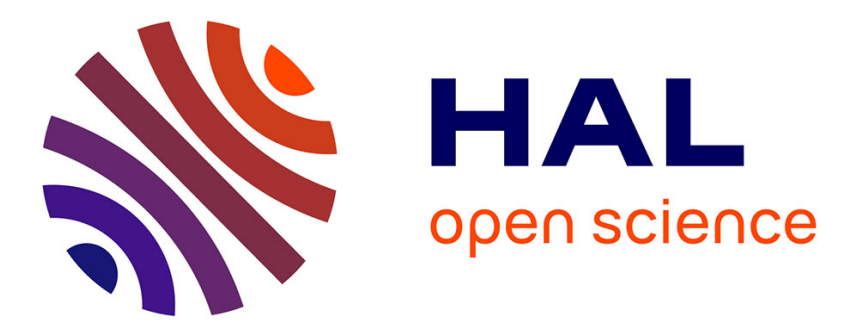

\title{
Realization and Characterization of Carbonic Layers on 4H-SiC for Electrochemical Detections
}

Julien Pezard, Véronique Soulière, Mihai Lazar, Naoufel Haddour, François Buret, Christophe Raynaud, Dominique Planson

\section{- To cite this version:}

Julien Pezard, Véronique Soulière, Mihai Lazar, Naoufel Haddour, François Buret, et al.. Realization and Characterization of Carbonic Layers on $4 \mathrm{H}-\mathrm{SiC}$ for Electrochemical Detections. Materials Science Forum, 2017, 897, pp.739 - 742. 10.4028/www.scientific.net/MSF.897.739 . hal-01644735

\section{HAL Id: hal-01644735 https://hal.science/hal-01644735}

Submitted on 6 May 2019

HAL is a multi-disciplinary open access archive for the deposit and dissemination of scientific research documents, whether they are published or not. The documents may come from teaching and research institutions in France or abroad, or from public or private research centers.
L'archive ouverte pluridisciplinaire HAL, est destinée au dépôt et à la diffusion de documents scientifiques de niveau recherche, publiés ou non, émanant des établissements d'enseignement et de recherche français ou étrangers, des laboratoires publics ou privés. 


\title{
Realization and characterization of carbonic layers on $4 \mathrm{H}-\mathrm{SiC}$ for electrochemical detections
}

\author{
J. Pezard ${ }^{1, a}$, V. Soulière ${ }^{2, b}$, M. Lazar ${ }^{1, c^{*}}$, N. Haddour ${ }^{1, d}$, F. Buret ${ }^{1, e}$, \\ C. Raynaud ${ }^{1, f}$, D. Planson ${ }^{1, g}$ \\ ${ }^{1}$ AMPERE, INSA Lyon, Ecole Centrale de Lyon, 69621 Villeurbanne, France \\ ${ }^{2}$ Laboratoire des Multimatériaux et Interfaces, Université Lyon 1, 69622 Villeurbanne, France \\ ajulien.pezard@ec-lyon.fr, bveronique.souliere@univ-lyon1.fr, 'mihai.lazar@insa-lyon.fr,

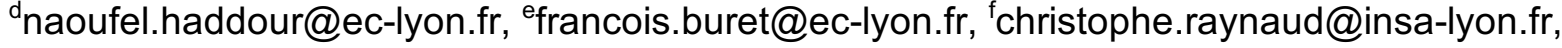 \\ gdominique.planson@insa-lyon.fr
}

Keywords: electrochemical sensors, carbonic layers, PPF, BDD, graphene.

\begin{abstract}
Carbon materials are considered building blocks for most of electrochemical sensors. Their biocompatibility allows their use as transducers for biosensors. Furthermore, they can be patterned, giving interest in all-inclusive bioelectrochemical detection devices. In particular, graphene, boron doped diamond, and pyrolyzed photoresist films are suitable for this kind of application, which would give the ability to use these working electrodes within a fully designed apparatus completed by counter and reference electrode. In this paper, a pioneer work is exposed on the synthesis of these materials for use as electrochemical sensors and as transducers for biodetection of acetylcholine by adsorption of acetylthiocholinesterase. The lowest limit of detection reaches $6.98 \mu \mathrm{M}$, sensitivity $5.91 \mu \mathrm{A} / \mathrm{mM}$, and a linear range from $6.98 \mu \mathrm{M}$ to $0.55 \mathrm{mM}$.
\end{abstract}

\section{Introduction}

For electrochemical use, carbon materials exhibit better behaviors than metallic gold or platinum electrodes, in terms of detection limit, potential range and sensitivity [1]. Another advantage of these materials is that they can be prepared at the surface of different substrates. In this work, we aim at preparing diamond, graphene and pyrolyzed photoresist films (PPF) at the surface of silicon carbide $(4 \mathrm{H}-\mathrm{SiC})$, which is considered to be a biocompatible material. These layers are more attractive than glassy carbon, a broadly used carbon material in electrochemistry. Our layers present the advantage to be able to be patterned, to resist to high temperature and also give the possibility to include all them in SiC technological steps for the preparation of more elaborate structures.

Discovered in 1984, fourteen years later, PPF has been used as a working electrode [2], showing interesting properties in terms of durability and reliability. Nowadays, PPF is used in research as a biocompatible working electrode for electrochemical analysis [3], or as a sensitive and selective electrode for heavy metals detections [4]. Del Campo et al. also showed the possibility to include PPF in CMOS technology [5]. PPF can be obtained by the pyrolysis of photoresist layers, by a plethora of conditions (temperature, duration, pressure, presence of different gas). In SiC technology, PPF is used as a protective cap during post-implantation annealing [6].

Graphene has shoved the world of electronics forward by its marvelous theoretical properties. In electrochemistry, its exceptional behavior in sensitivity and limit of detection [7] has attracted the attention of researchers. In this study we focused on graphene grown on SiC by silicon sublimation at its surface. This material has promising characteristics, in particular, a good signal to noise ratio.

Diamond is well known in electrochemistry for its very large potential range, but also a far higher signal to noise ratio than for glassy carbon [8]. Diamond in electrochemistry needs to be conductive enough and in this sense it is heavily doped with boron. The common name used is Boron doped diamond (BDD). These electrodes show a reproductive behavior through time and show no damage of the layer with long term use.

* corresponding author 
In our work, performances of these electrodes have been evaluated and compared. Furthermore, an application of these layers as transducers in the detection of a biological molecule (Acetylthiocholine) is shown. The results obtained give real confidence to our team that these layers show a real interest in the field in electrochemistry.

\section{Experimental}

Pyrolyzed photoresist films were obtained by the annealing of AZ5214E photoresist at temperatures above $1000{ }^{\circ} \mathrm{C}$, which is higher than what can be generally found in literature [2-5]. PPF layers have been synthetized by spin coating depositing on SiC of AZ5214E photoresist film with a thickness of approximately $1 \mu \mathrm{m}$. Then, solvents are evaporated and the resist is pyrolyzed under primary vacuum at $750{ }^{\circ} \mathrm{C}$ for 30 minutes. A second annealing is performed with an induction RTA furnace during 30 minutes, under Ar, with a temperature plateau we varied from 1150 to $1650{ }^{\circ} \mathrm{C}$. Graphene has been synthesized by sublimation of $\mathrm{Si}$ from $\mathrm{SiC}$ at $1550{ }^{\circ} \mathrm{C}$ under Ar atmosphere with the same induction RTA furnace. Details upon this method can be found elsewhere [9]. Boron Doped Diamond has been deposited on SiC by plasma-assisted chemical vapour deposition (PACVD) [10]. All the carbonic layers have been formed on $4 \mathrm{H}-\mathrm{SiC}$ commercial substrates with low doped n-type epilayers provided from $\mathrm{CREE}^{\mathrm{TM}}$. The presence of the low-doped epilayer was necessary to select the response of the carbonic layers from that of the SiC substrate.

For this study, the layers' conductivities have been evaluated through I-V four-point probe method measurements at room temperature. Their electrochemical properties in terms of kinetics, potential range, detection limit, sensitivity and signal to noise ratio were studied by electrochemical characterizations with an Origalys OGS 100 potentiostat. Acetylcholinesterase, chitosan, and Dulbecco's Phosphate Buffered Saline (PBS) 10X were purchased from Sigma Aldrich. $\mu$-Raman measurements were performed using the $633 \mathrm{~nm}$ wavelength of an HeNe laser beam (LabRAM ARAMIS HORIDA $20 \mathrm{~mW}$ ).

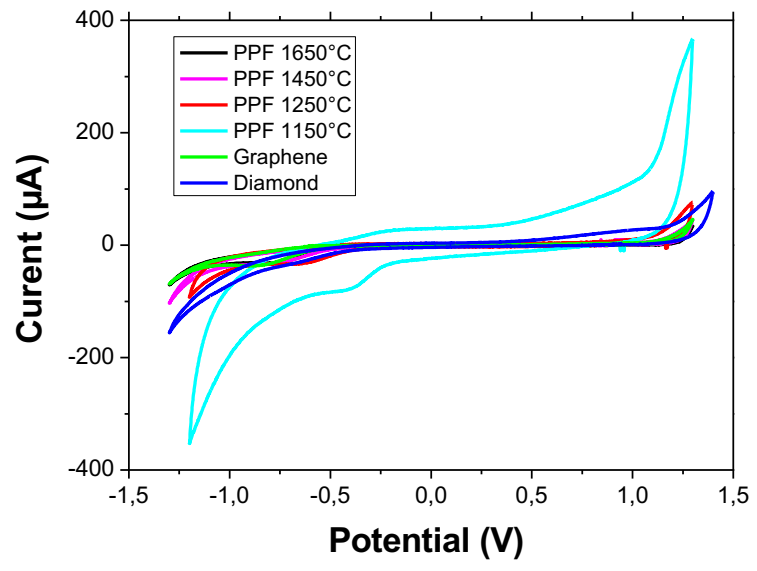

Fig.1 Cyclic voltammetry corresponding to the electroactivity of our electrodes in PBS 10X

\begin{tabular}{|c|c|c|}
\hline Electrode & $\begin{array}{c}\text { Potential } \\
\text { windowin } \mathrm{KCl} \\
\text { PPF annealed } 1150^{\circ} \mathrm{C}\end{array}$ & $\begin{array}{c}\text { Potential } \\
\text { window in PBS } \\
\text { 10v }\end{array}$ \\
\hline PPF annealed $1250^{\circ} \mathrm{C}$ & $-1.5-1.1 \mathrm{~V}$ & $-1.08-1.05 \mathrm{~V}$ \\
\hline PPF annealed $1450^{\circ} \mathrm{C}$ & $-1.4-1.37 \mathrm{~V}$ & $-1.2-1.15 \mathrm{~V}$ \\
\hline PPF annealed $1650^{\circ} \mathrm{C}$ & $-1.6-1.39 \mathrm{~V}$ & $-1.4-1.25 \mathrm{~V}$ \\
\hline Graphene & $-1.4-1.39 \mathrm{~V}$ & $-1.4-1.25 \mathrm{~V}$ \\
\hline Diamond & $-1-1.37 \mathrm{~V}$ & $-1.1-1.25 \mathrm{~V}$ \\
\hline
\end{tabular}

Table 1 . The electroactivity potential range values for our electrodes in $\mathrm{KCl} 0.1 \mathrm{M}$ and PBS 10X

\section{Results and discussion}

Figure 1 and Table 1 present the electroactivity potential domains of our electrodes in $\mathrm{KCl} 0.1$ $\mathrm{M}$ (Molarity $=$ moles/volume) and in PBS $10 \mathrm{X}$. For the PPF, the electroactivity range increases with the annealing temperature. This is in agreement with the increasing of the electrical conductivity of the PPF layers with the annealing temperature, as we obtained by I-V measurements. Figure 2 presents linear I-V characteristics obtained by four-point method and the extracted resistivity of the PPF layers versus annealing temperature. The thicknesses of the PPF layers have been accurately measured by alpha-step stylus profilometer. Both the resistivity and the thicknesses of the PPF layers decrease by increasing the annealing temperature. The thickness variation is related to a disorder evolution which is also observed by structural Raman analyses presented in Fig.3 and Table 2. The relative intensity variation between the peaks $D$ and $G$ indicates a change in the 
structure of the PPF layers. The optimal annealing temperature can be considered at $1650^{\circ} \mathrm{C}$ which is close to the temperature of our graphene growth on SiC. The PPF and graphene layers could be generated on $\mathrm{SiC}$ during the same technological step.
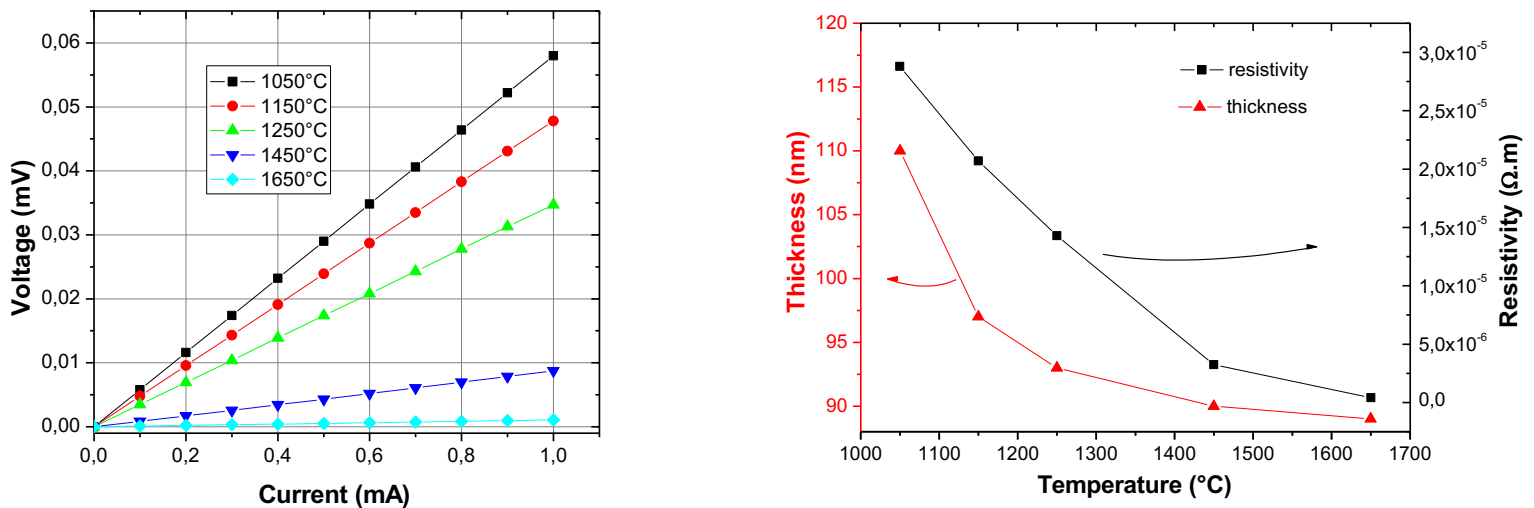

Fig2. Four-probe I-V measurements on PPF layers and the extracted resistivities versus the temperature annealing.
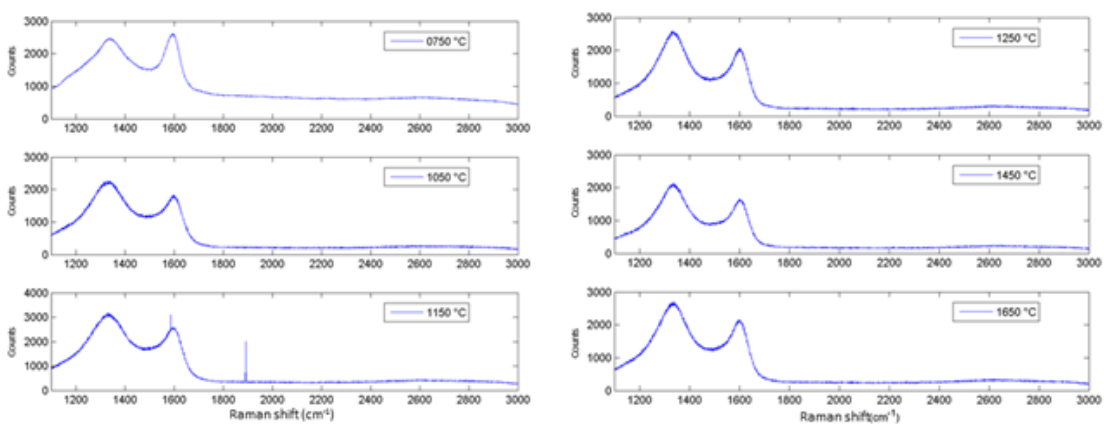

Fig.3 Raman analyses of PPF layers formed at varied annealing temperatures from $750^{\circ} \mathrm{C}$ to $1650^{\circ} \mathrm{C}$

\begin{tabular}{|l|l|}
\hline $\mathbf{T}\left({ }^{\circ} \mathbf{C}\right)$ & $\mathbf{I}_{\mathbf{D}} / \mathbf{I}_{\mathbf{G}}$ \\
\hline 750 & 0.946 \\
\hline 1050 & 1.235 \\
\hline 1150 & 1.25 \\
\hline 1250 & 1.265 \\
\hline 1450 & 1.275 \\
\hline 1650 & 1.289 \\
\hline
\end{tabular}

Table 2. Relative intensity variation between the peaks D and G extracted from Raman analyses on PPF layers.

Figures 4 presents the Michaelis-Menten and Lineweaver Burk calibration curves from our electrodes ( $1 \mathrm{~cm}^{2}$ samples), used as biosensors for detection of acetylthiocholine in PBS 10X. Prior to electrochemical detection, the electrodes have been functionalized by adsorption using a solution of chitosan $0.5 \%$ in acetic acid adjusted to $\mathrm{pH} 5$ with $\mathrm{NaOH}$.
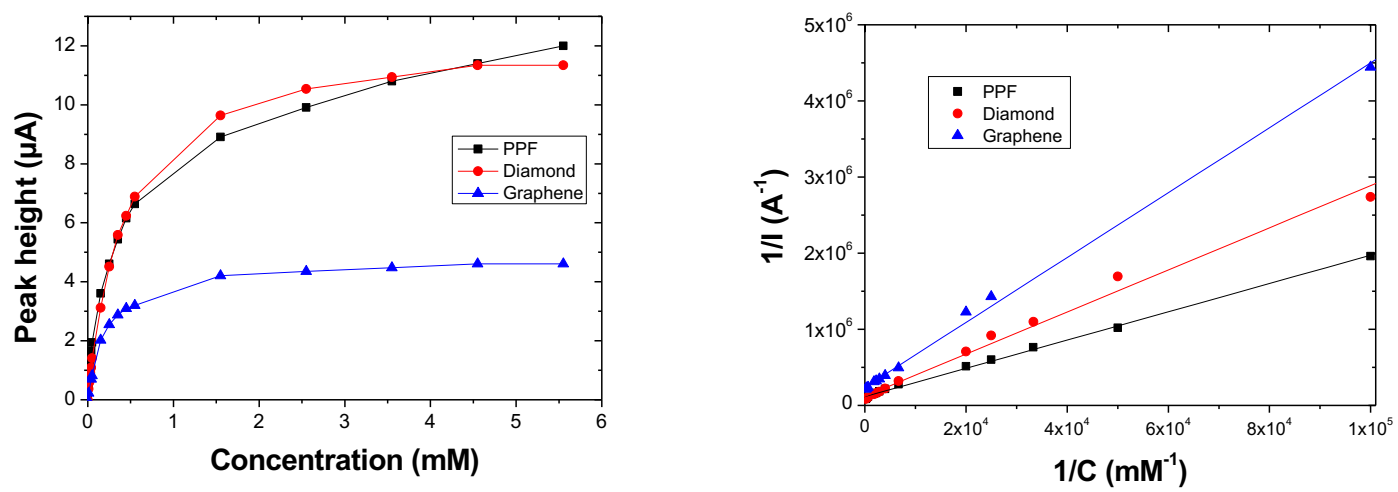

Fig 4 Michaelis-Menten (left) and Lineweaver Burk (right) calibration curves extracted from chronoamperometry for detection of acetylthiocholine

Table 3 resumes the biosensors characteristics obtained with our carbonic electrodes: reaction speed ( $\left.i_{\max }\right)$, Michaelis Menten constant $\left(\mathrm{K}_{\mathrm{M}}\right)$, limit of detection, sensitivity and linearity range.

For the all three materials the $\mathrm{K}_{\mathrm{M}}$ constant is in the same range of values, the fixed enzyme exhibiting the same activity. On a biosensor based on carbon nanotube films functionalized with the same enzyme and employing a redox mediator Chen et al. [11] obtained a Michaelis constant of $0.25 \mathrm{mM}$, which is relatively close to our results. Li et al. showed a constant of $0.77 \mathrm{mM}$ for the detection of acetylthiocholine on graphene electrode [12]. In our study, we aim at having the lowest Michaelis constant, as a low value stands for a maximum enzyme activity reached with low substrate concentrations. In terms of sensitivity, compared to graphene, PPF and diamond exhibit 
superior values. Our results are relatively close to the literature where the sensitivity is around $10 \mu \mathrm{A} / \mathrm{mM}$ [13]. The detection limit observed on our three materials is between 7 to $30 \mu \mathrm{M}$. The best threshold values were obtained with graphene. These values correspond to the detection limits described in the literature for electrodes unmodified with mediators. For example, functionalized graphene has allowed obtaining a detection limit of $3 \mu \mathrm{M}$ [14]. Kesik et al. obtained a limit of 0.09 $\mathrm{mM}$ for carbon nanotubes, and a linearity range from $0.05 \mathrm{mM}$ to $8 \mathrm{mM}$ [15].

\begin{tabular}{|c|c|c|r|}
\hline & PPF & Graphene & \multicolumn{1}{c|}{ Diamant } \\
\hline $\mathrm{i}_{\max }(\mathrm{A})$ & $8.67 \mathrm{E}-06 \pm 2.25 \mathrm{E}-08$ & $4.20 \mathrm{E}-06 \pm 4.15 \mathrm{E}-08$ & $8.31 \mathrm{E}-06 \pm 2.08 \mathrm{E}-08$ \\
\hline $\mathrm{K}_{\mathrm{M}}(\mathrm{mM})$ & $0.161 \pm 4.19 \mathrm{E}-04$ & $0.179 \pm 17.6 \mathrm{E}-04$ & $0.23 \pm 5.75 \mathrm{E}-04$ \\
\hline Detection limit $(\mathrm{M})$ & $2.98 \mathrm{E}-05 \pm 7.76 \mathrm{E}-08$ & $6.98 \mathrm{E}-06 \pm 6.98 \mathrm{E}-08$ & $2.28 \mathrm{E}-05 \pm 5.70 \mathrm{E}-08$ \\
\hline Sensitivity $(\mu \mathrm{A} / \mathrm{mM})$ & $11.21 \pm 0.58$ & $5.91 \pm 0.67$ & $12.83 \pm 0.44$ \\
\hline Linear range $(\mathrm{M})$ & $2.98 \mathrm{E}-05$ to $0.55 \mathrm{E}-03$ & $6.98 \mathrm{E}-06$ to $0.55 \mathrm{E}-03$ & $2.28 \mathrm{E}-05$ to $0.45 \mathrm{E}-03$ \\
\hline
\end{tabular}

Table 3. The electrochemical characteristics values for our electrodes used as transducers in a biosensor

\section{Conclusion}

The layers grown in this study have shown electrochemical behavior comparable with literature, with wide potential range, and the possibility to use them for biodetection was outlined through the detection of acetylthiocholine in chronoamperometry in a concentration range that fits with biological detection needs. The materials used for the development of our electrodes can be easily patterned, one asset that enables us to predict multiple aspects that could be investigated in the future. One of them would be to reduce the size of these electrodes from macrometric to micrometric dimensions in order to use them in all-inclusive devices with compatible technological steps as PPF and graphene generated on SiC during the same annealing.

\section{Acknowledgements}

The authors gratefully thank Dr Alexandre Tallaire from LSPM for the diamond films deposition by plasma-assisted CVD on our SiC samples.

\section{References}

[1] C. E. Nebe et al., J. Phys. D. Appl. Phys., vol. 40, no. 20, pp. 6443-6466, 2007.

[2] J. Kim et al., J. Electrochem. Soc., vol. 145, no. 7, p. 2314, 1998.

[3] S. T. Larsen et al., ECS Electrochem. Lett., vol. 2, no. 5, pp. B5-B7, 2013.

[4] A. Mardegan et al., Electroanalysis, vol. 27, pp. 128-134, 2015.

[5] F. J. del Campo et al., J. Electrochem. Soc., vol. 158, no. 1, p. H63, 2011.

[6] Y. Negoro et al: Materials Science Forum 483-485 (2005), p.599.

[7] F. Schedin et al., Nat. Mater., vol. 6, no. 9, pp. 652-655, 2007.

[8] J. W. Strojek et al., Anal. Chem., vol. 68, pp. 2031-2037, 1996.

[9] J.Pezard et al., Thin Solid Films, in press, accepted manuscript, doi:10.1016/j.tsf.2016.04.031

[10] A.Tallaire et al., Phys. Status Solidi A 208 No. 9 (2011) 2028-2032

[11] H. Chen et al., Analyst, vol. 133, no. 9 (2008) 1182-1186, 2008

[12] Y. Li and G. Han, Analyst, vol. 137, no. August (2012) 3160, 2012.

[13] D. Du et al., Anal. Bioanal. Chem., vol. 387, (2007) 1059-1065.

[14] H. Zhang et al., Anal. Chim. Acta, vol. 827 (2014) 86-94.

[15] M. Kesik et al., Sensors Actuators B Chem., vol. 205, (2014) 39-49. 